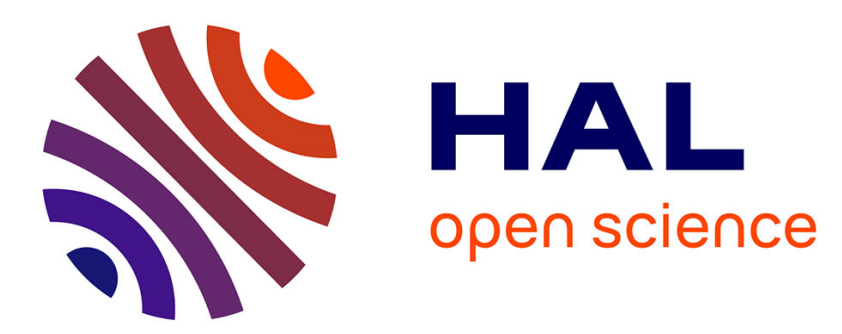

\title{
A Minimization of Speed Ripple of Sensorless DTC for controlled Induction Motors used in Electric Vehicles
}

Farid Khoucha, Khoudir Marouani, Abdelaziz Kheloui, Mohamed Benbouzid

\section{To cite this version:}

Farid Khoucha, Khoudir Marouani, Abdelaziz Kheloui, Mohamed Benbouzid. A Minimization of Speed Ripple of Sensorless DTC for controlled Induction Motors used in Electric Vehicles. IEEE IECON'06, Nov 2006, Paris, France. pp.1339-1344. hal-00526700

\section{HAL Id: hal-00526700 https://hal.science/hal-00526700}

Submitted on 15 Oct 2010

HAL is a multi-disciplinary open access archive for the deposit and dissemination of scientific research documents, whether they are published or not. The documents may come from teaching and research institutions in France or abroad, or from public or private research centers.
L'archive ouverte pluridisciplinaire HAL, est destinée au dépôt et à la diffusion de documents scientifiques de niveau recherche, publiés ou non, émanant des établissements d'enseignement et de recherche français ou étrangers, des laboratoires publics ou privés. 


\title{
A Minimization of Speed Ripple of Sensorless DTC for controlled Induction Motors used in Electric Vehicles
}

\author{
F. Khoucha ${ }^{1}$, K. Marouani ${ }^{1}$, A. Kheloui ${ }^{1}$, MEH. Benbouzid ${ }^{2}$ \\ 1-UER-Electrotechnique, EMP, BP17-16111-Bordj El-Bahri, Algiers, Algéria \\ 2-LIME, IUT of Brest, University of Western Brittany - Rue de Kergoat - BP 93169, 29231 Brest Cedex 3, France \\ Email : fkhoucha04@yahoo.fr \\ Fax n: +21321863204
}

\begin{abstract}
- the main theme of this paper is to present different switching techniques in DTC induction motor drives for electric vehicle applications, witch insert zero-voltage vector and/or more non zero-voltage vectors to the conventional switching table associated to full adaptive flux and speed observer. Those techniques are quite effective in reducing the torque pulsation and the speed ripples of the motors, as demonstrated in experimental results.
\end{abstract}

Keywords-Direct Torque Control (DTC), induction motors drives, adaptive observer.

\section{Introduction}

In the last decade, the increasing restrictions imposed on the exhaust emissions from internal combustion engines and the traffic limitations in the urban areas have given a strong impulse toward the development of electrical propulsion systems for automotive applications. The goal of electrical and hybrid vehicles is the reduction of global emissions, which in turn leads to a decrease of fuel resources exploitation.

The major components of an electric vehicle system are motor, controller, power source; charger and drive train. The majority of electric vehicles (EV) developed so far are based on dc machines, induction machines or permanent magnet machines. The disadvantages of dc machines forced the EV developers to look into various types of ac machines. The power density of permanent magnet machines together with the high cost of permanent magnets makes these machines less attractive for EV applications. The maintenance-free and low-cost induction machines became an attractive alternative to many developers. However, high-speed operation of induction machines is only possible with a penalty in size and weight. Threephase squirrel cage-rotor induction motors are best suited to electric vehicle drive applications thanks to its well-known advantage of simple construction, reliability, ruggedness, and low cost.

Induction motor drives control techniques are well treated in the literature. The most popular is the so-called vector control technique that is now used for high impact automotive applications (EV and $\mathrm{HEV}$ ). In this case, the torque control is extended to transient state and allows

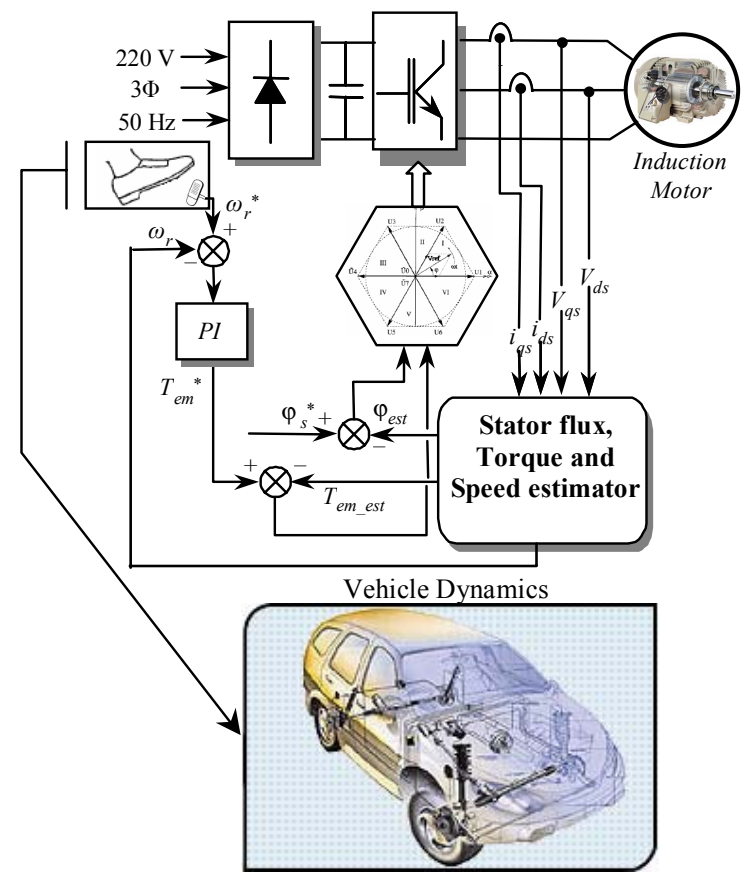

Fig.1 Basic Direct Torque Control Scheme

better dynamic performances. Among these techniques, DTC $[1,2]$ appears to be very convenient for EV and HEV applications. DTC has the advantage of not requiring speed or position encoders and uses voltage and current measurements only. Flux, torque, and speed are estimated. It also has a faster dynamic response due to the absence of the PI current controller and minimizes the use of machine parameters [3]. The input of the motor controller is the reference speed, which is directly applied by the pedal of the vehicle.

One of the disadvantages of conventional DTC is high torque ripple. Several techniques have been developed to reduce the torque ripple. One of them is duty ratio control method. In duty ratio control, a selected output voltage vector is applied for a portion of one sampling period, and a zero voltage vector is applied for the rest of the period.. The pulse duration of output voltage vector is determined by the torque-ripple minimum condition. These improvements can greatly reduce the torque ripple, but they increase the complexity of DTC algorithm. 
An alternative method to reduce the ripples is based on space vector modulation (SVM) technique $[4,5]$. At each cycle period, a preview technique is used to obtain the voltage space vector required to exactly compensate the flux and torque errors. The required voltage space vector can be synthesized using SVM technique.

SVM-DTC is significantly improved. However, it requires calculating several complicate equations online, and it depends on more machine parameters. Casadei et al. [6] presented a new DTC scheme using discrete space vector modulation (DSVM) technique. It is a control system able to generate a number of voltage vectors higher than that used in conventional DTC scheme. The increased number of voltage vectors allows the definition of more accurate switching tables. The DSVM-DTC achieves a sensible reduction of torque ripple, without increasing the complexity of conventional DTC.

\section{Conventional DTC Principle}

The basic model of DTC induction motor scheme is shown in Fig. 1. At each sample time, the two stator current $i_{S A}$ and $i_{S B}$ and DC-bus voltage $\mathrm{V}_{\mathrm{dc}}$ are sampled. Using the inverter voltage vector $\overline{S_{a} S_{b} S_{c}}$, the $\alpha-\beta$ components of the stator voltage space vector in the stationary reference frame are calculated as shown in (1) and (2).

$$
\begin{aligned}
& V_{s \alpha}=\frac{2}{3} V_{d c}\left(S_{a}-\frac{S_{b}+S_{C}}{2}\right) \\
& V_{s \beta}=\frac{1}{\sqrt{3}} V_{d c}\left(S_{b}-S_{c}\right)
\end{aligned}
$$

The $\alpha-\beta$ components of the stator current space vector are calculated using equations (3) and (4).

$$
\begin{aligned}
& i_{s \alpha}=i_{S A} \\
& i_{s \beta}=\frac{{ }^{i}+2 i_{S B}}{\sqrt{3}}
\end{aligned}
$$

\section{Stator flux estimation}

In the stationary reference frame fixed on stator, the dynamic behaviour of induction motor can be described by the following model.

$$
\begin{aligned}
& \left\{\begin{array}{l}
\dot{x}=A x+B u \\
y=C x
\end{array}\right. \\
& \text { Where } x=\left[\begin{array}{llll}
i_{s \alpha} & i_{s \beta} & \varphi_{r \alpha} & \varphi_{r \beta}
\end{array}\right]^{t} \\
& u=\left[\begin{array}{ll}
v_{s \alpha} & v_{s \beta}
\end{array}\right]^{t} \quad y=\left[\begin{array}{ll}
i_{s \alpha} & i_{s \beta}
\end{array}\right]^{t}
\end{aligned}
$$

$$
\begin{gathered}
A=\left[\begin{array}{cccc}
-\frac{1}{\sigma}\left(\frac{1-\sigma}{T_{r}}+\frac{1}{T_{S}}\right) & 0 & \frac{M}{\sigma L_{r} L_{S} T_{r}} & \frac{M}{\sigma L_{r} L_{S}} \omega_{r} \\
0 & -\frac{1}{\sigma}\left(\frac{1-\sigma}{T_{r}}+\frac{1}{T_{S}}\right) & -\frac{M}{\sigma L_{r} L_{S}} \omega_{r} & \frac{M}{\sigma L_{r} L_{S} T_{r}} \\
\frac{L_{m}}{T_{r}} & 0 & -\frac{1}{T_{r}} & -\omega_{r} \\
0 & \frac{L_{m}}{T_{r}} & \omega_{r} & -\frac{1}{T_{r}}
\end{array}\right] \\
B=\left[\begin{array}{cc}
\frac{1}{\sigma L_{r}} & 0 \\
0 & \frac{1}{\sigma L_{r}} \\
0 & 0 \\
0 & 0
\end{array}\right] \quad C=\left[\begin{array}{llll}
1 & 0 & 0 & 0 \\
0 & 1 & 0 & 0
\end{array}\right]
\end{gathered}
$$

A linear state for the stator flux can then be derived as following, by considering the mechanical speed as constant parameter.

$$
\hat{\dot{x}}_{s}=A \hat{x}+B U+K\left(\hat{i}_{s}-i_{s}\right)
$$

The symbol ${ }^{\wedge}$ denotes an estimated quantity. $K$ is a gain matrix, which is used to suitably locate the observer's poles.

Using Lyapounov stability theory, we can construct a mechanism to adapt the mechanical speed from the asymptotic convergence's condition of the state variables estimation errors:

$$
\hat{\omega}_{s}=-K_{i \omega} \int\left(e_{s \alpha} \hat{\varphi}_{r \alpha}+e_{s \beta} \hat{\varphi}_{r \beta}\right) d t-K_{p \omega}\left(e_{s \alpha} \hat{\varphi}_{r \alpha}+e_{s \beta} \hat{\varphi}_{r \beta}\right)
$$

$$
\text { Where } e_{s \alpha}=i_{s \alpha}-\hat{i}_{s \alpha} \text { and } e_{s \beta}=i_{s \beta}-\hat{i}_{s \beta} \text {. }
$$

$K_{i \omega}$ and $K_{p \omega}:$ are positive gains.

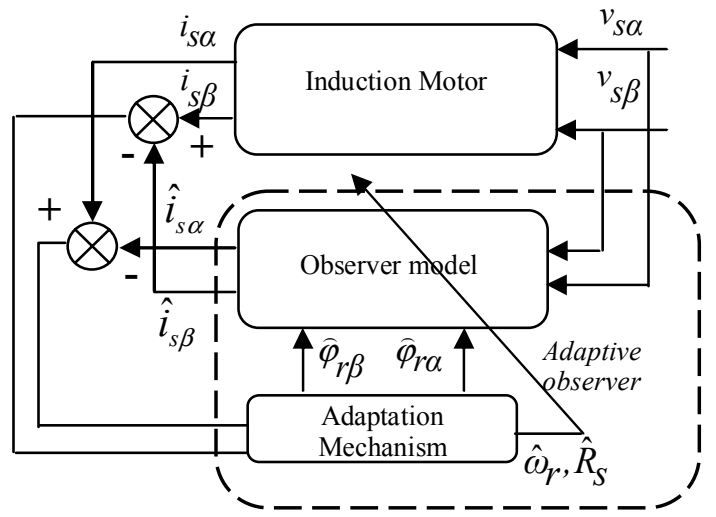

Fig. 2 Global adaptive observer structure 
The stator flux is a function of the rotor flux which represented by.

$$
\left\{\begin{array}{l}
\varphi_{s \alpha}=\sigma L_{s} i_{s \alpha}+\frac{M}{L_{r}} \varphi_{r \alpha} \\
\varphi_{s \beta}=\sigma L_{s} i_{s \beta}+\frac{M}{L_{r}} \varphi_{r \beta}
\end{array}\right.
$$

Then using equations (10) and (11), the magnitude of the stator flux and electric torque are calculated.

$$
\begin{aligned}
& \left|\varphi_{S}\right|=\sqrt{\varphi_{s \alpha}^{2}+\varphi_{s \beta}^{2}} \\
& T_{e}=\frac{3}{2} p\left(\varphi_{s \alpha^{i}} i_{s}-\varphi_{s \beta i_{s}}\right)
\end{aligned}
$$

Where $p$ is the number of pole pairs,

Fig .1 shows the block diagram of DTC-based IM drive. As shown in Fig .3, a switching table is used for inverter control such that the torque and flux errors are kept within the specified bands.

The errors of torque and flux are indicated by $\Delta T_{e}$ and $\Delta \varphi_{s}$ respectively, and defined as

$$
\begin{aligned}
& \Delta T_{e}=T_{e}-\hat{T}_{e} \\
& \Delta \varphi_{s}=\varphi_{s}-\hat{\varphi}_{s}
\end{aligned}
$$

And the inverter switching states are determined by the errors of torque and flux according to the sector determined.

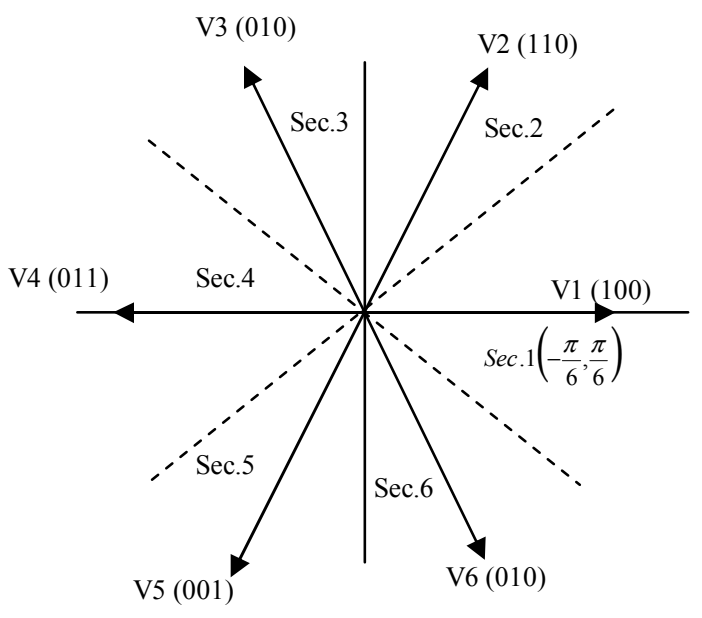

a. Output voltage vectors

\begin{tabular}{|c|c|c|c|c|c|c|c|}
\hline & & $\begin{array}{l}0 \\
\stackrel{0}{0} \\
\stackrel{0}{J} \\
\mathscr{\omega}\end{array}$ & 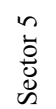 & 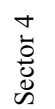 & 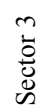 & 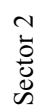 & 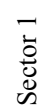 \\
\hline & & $\begin{array}{l}\text { } \\
\stackrel{9}{1} \\
\stackrel{8}{\circ} \\
\stackrel{1}{9}\end{array}$ & $\begin{array}{l}\stackrel{\bigcirc}{\circ} \\
\stackrel{m}{0} \\
\stackrel{9}{0}\end{array}$ & $\begin{array}{l}\stackrel{\bigcirc}{\circ} \\
\stackrel{\circ}{\circ} \\
\stackrel{0}{0}\end{array}$ & $\begin{array}{l}\stackrel{\circ}{\circ} \\
\stackrel{\circ}{\circ}\end{array}$ & 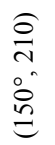 & 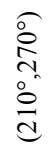 \\
\hline \multirow{2}{*}{$\begin{array}{c}\text { Decrease } \\
\text { Flux }\end{array}$} & $\begin{array}{c}\text { Increase } \\
\text { Torque }\end{array}$ & 100 & 110 & 010 & 011 & 001 & 101 \\
\hline & $\begin{array}{c}\text { Decrease } \\
\text { Torque }\end{array}$ & 011 & 001 & 101 & 100 & 110 & 010 \\
\hline \multirow{2}{*}{$\begin{array}{l}\text { Increase } \\
\text { Flux }\end{array}$} & $\begin{array}{c}\text { Increase } \\
\text { Torque }\end{array}$ & 110 & 010 & 011 & 001 & 101 & 100 \\
\hline & $\begin{array}{c}\text { Decrease } \\
\text { Torque }\end{array}$ & 001 & 101 & 100 & 110 & 010 & 011 \\
\hline
\end{tabular}

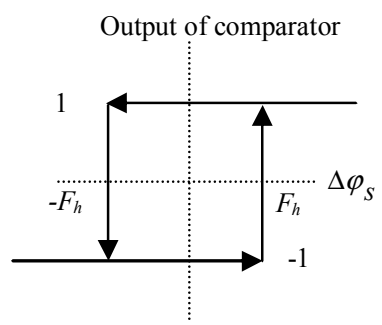

b. Flux comparator

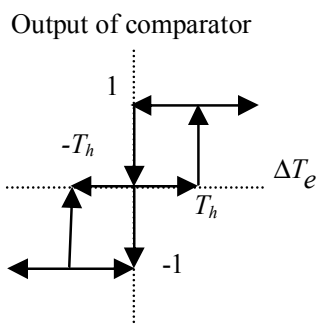

c. Three Level torque comparator d. Switching table

Fig.3. Definition of switching state and comparator for classical DTC

\section{DSVM DTC Technique}

DSVM technique uses a standard VSI and synthesizes a higher number of voltage vectors than those used in conventional DTC. The implementation of the DSVM technique requires only a small increase of the computational time required by conventional DTC scheme.

In DSVM-DTC, one sampling period is divided into $m$ equal time intervals. One of the VSI voltage vectors is applied in each of them. The number of voltage vectors, which can be generated, is directly related to $m$. The higher is $m$, the higher is the number of voltage vectors and the lower is the amplitude of the current and torque ripple, but more complex are the switching tables required. A good compromise between the errors compensation and the complexity of the switching tables is achieved by choosing $m=3[7,8]$.

Using DSVM technique with three equal time intervals, 36 synthesized non-zero voltage vectors are obtained. The stator flux is assumed to be in sector 1 , then 19 voltage vectors can be used, as represented in Fig. 4.a. The black dots represent the ends of the synthesized voltage vectors. As an example, the label "556" denotes the voltage vector which is synthesized by using the standard VSI voltage vectors V5, V5 and V6, each one applied for one third of the sampling period, where ' $Z$ ' denotes a zero voltage vector.

In order to fully utilize the available voltage vectors, one sector is subdivided into two parts, as shown in Fig. 3.a, because the torque reduction produced by a zero VSI voltage vector is much more evident at high speed, different voltage vectors are chosen for different speed range [7]. When the rotor speed is greater than one half of the synchronous speed, it belongs to high speed range. When 
the rotor speed is lower than one sixth of the synchronous speed, it is in low speed range.

The switching tables used in DSVM-DTC are reported in Fig. 4.b, where $C_{\varphi}$ and $C_{\mathrm{T}}$ are the outputs of flux and torque hysteresis controllers. $C_{\varphi}$ has two levels. $C_{\varphi}=-1$ means that the amplitude of the stator flux exceeds the upper limit of its hysteresis band and should be reduced

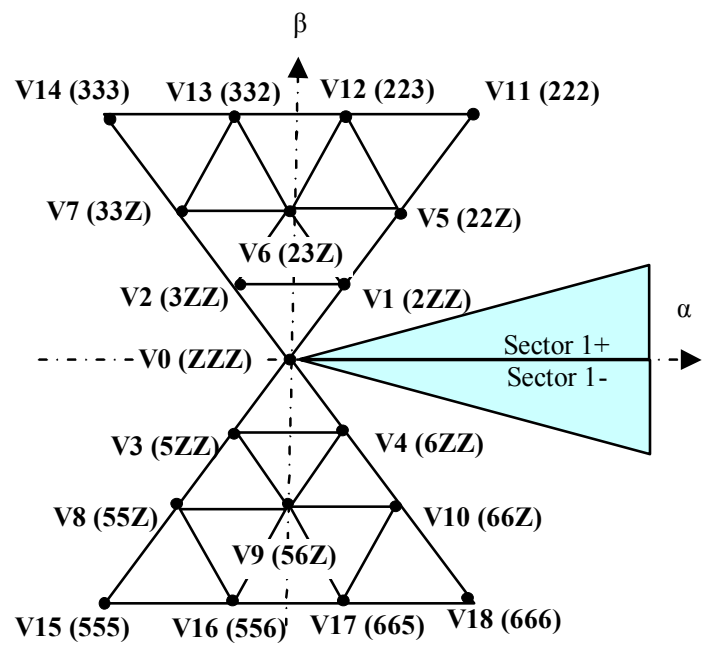

a) Synthesized voltage vectors obtained by using DSVM technique

\begin{tabular}{|c|c|c|c|c|c|c|}
\cline { 2 - 7 } \multicolumn{1}{c|}{} & \multirow{2}{c|}{$C_{\varphi}$} & \multicolumn{5}{|c|}{$C_{T}$} \\
\cline { 2 - 7 } \multicolumn{1}{c|}{} & -2 & -1 & 0 & +1 & +2 \\
\cline { 2 - 7 } Low speed range & +1 & 555 & $5 \mathrm{ZZ}$ & $\mathrm{ZZZ}$ & $3 \mathrm{ZZ}$ & 333 \\
\hline \multirow{2}{*}{ Middle speed range } & -1 & 555 & $6 \mathrm{ZZZ}$ & $\mathrm{ZZZ}$ & $2 \mathrm{ZZ}$ & 222 \\
\cline { 2 - 7 } & +1 & 666 & $\mathrm{ZZZ}$ & $3 \mathrm{ZZZ}$ & $33 \mathrm{ZZ}$ & 333 \\
\hline \multirow{2}{*}{$\begin{array}{c}\text { High speed range, } \\
\text { sector 1+ }\end{array}$} & -1 & 555 & $3 \mathrm{ZZ}$ & $33 \mathrm{Z}$ & 333 & 222 \\
\cline { 2 - 7 } & +1 & 666 & $2 \mathrm{ZZ}$ & $23 \mathrm{Z}$ & 223 & 222 \\
\hline $\begin{array}{c}\text { High speed range, } \\
\text { sector 1- }\end{array}$ & -1 & 555 & $3 \mathrm{ZZ}$ & $23 \mathrm{Z}$ & 332 & 333 \\
\cline { 2 - 7 } & +1 & 666 & $2 \mathrm{ZZ2}$ & $22 \mathrm{Z}$ & 222 & 222 \\
\hline
\end{tabular}

b) Switching tables for DSVM-DTC scheme (stator flux in sector 1)

Fig.4. Definition of switching state and comparator for modified DTC
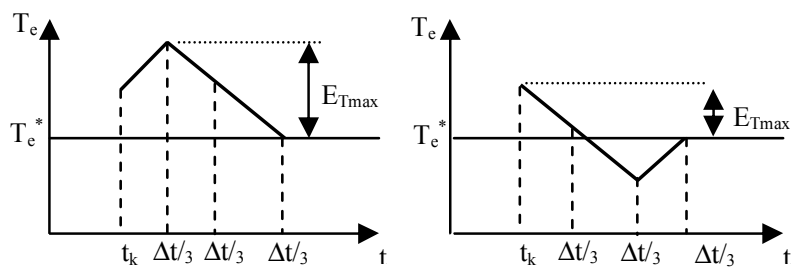

Fig 5 Comparison of torque waveforms in one sampling period when $C_{\mathrm{T}}$ is -1 : (a) applying " $3 Z Z$ "; (b) applying "ZZ3".
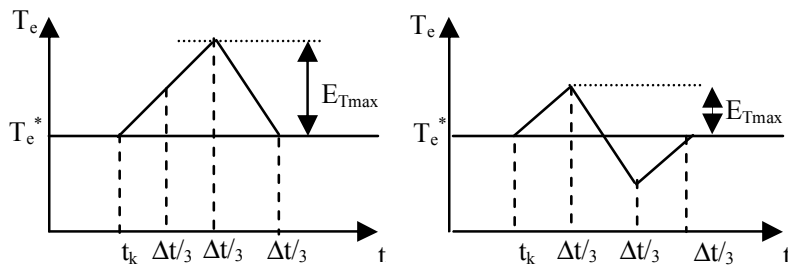

Fig 6 Comparison of torque waveforms in one sampling period when $C_{\mathrm{T}}$ is -1 : (a) applying " $3 Z Z$ "; (b) applying "ZZ3".
.Conversely, $C_{\varphi}=+1$ means the amplitude of the stator flux should be increased. $C_{\mathrm{T}}$ has five levels. The negative value of $C_{\mathrm{T}}$ means the torque needs decrease, and the positive value of $C_{\mathrm{T}}$ means the torque needs increase. When $C_{T}$ is -2 or +2 , the torque is far away from its command value, and needs a large, rapid change. When $C \mathrm{~T}$ is 0 , the torque is equal to or close to its command value, and should keep its value unchanged.

For example, it is assumed that the rotor speed is in high speed range, and stator flux vector is in sector $1+$. If $C_{\varphi}$ is -1 and $C_{T}$ is -2 , the stator flux needs decrease and the torque needs a large decrease, so V15 (555) is chosen. If $C_{\varphi}$ is +1 and $C_{T}$ is -1 , the stator flux needs increase and the torque needs a small decrease. Considering that a zero VSI voltage vector can evidently reduce the torque in high speed range, V1 (2ZZ) is chosen.

Changing the sequence of the 3 voltage vectors applied to the three equal time intervals of one sampling period does not change the final synthesized voltage vector. For example, (66Z), (6Z6) and (Z66) synthesize the same voltage vector V10. However, the sequence can greatly affect the torque ripple. If the 3 voltage vectors in one sampling period are applied in proper sequence, the torque ripple can be reduced.

It is assumed that the rotor speed is in high speed range, and stator flux vector is in sector $1+$. At time $t_{k}$, the beginning of a sampling period, $C_{\varphi}$ is -1 and $C_{T}$ is -1 , which indicates that the actual torque value is greater than the reference torque value. The torque should be decreased. In this case, " $3 Z Z$ " is selected according to Fig. 4.b. Applying VSI voltage vector $\mathrm{V} 3$ can increase the torque, and a zero voltage vector causes a decrement. If V3 is firstly applied, the torque error will be enlarged. The torque waveform is shown in Fig. 5(a), where $\Delta t$ is a sampling period time. In contrast, the torque waveform by applying "ZZ3" is shown in Fig. 5(b). Zero voltage vectors are firstly applied, causing the direct decrease of the torque. The torque error will not become larger. It can be seen from Fig. 5 that the maximum torque error $E_{\text {Tmax }}$ produced by "ZZ3" is smaller than that produced by " $3 Z Z$ ".

If $C_{T}$ is 0 in the previous case, the actual torque value is equal to or close to the reference torque value. " $33 Z$ " is selected according to Table 1 . The torque waveform is shown in Fig. 6(a). The torque increases to its maximum value, then decreases to the reference value. In order to minimize the torque ripple, the sequence of the 3 voltage vectors is changed, and " $3 Z 3$ " is used. Applying " $3 Z 3$ ", the torque increases firstly, and decreases in the second time interval.

In the third time interval the torque increases to its reference value, as shown in Fig. 6(b). The torque cannot reach the maximum value produced by " $33 Z$ ".

Therefore, the synthesized voltage vectors are selected from Fig. 4.b, but the sequence of their three components should be rearranged to reduce the torque ripple. When the torque needs decrease, the VSI voltage vectors which can decrease the torque should be firstly applied. Conversely, when the torque needs increase, the VSI voltage vectors which can increase the torque should be firstly applied. When the 
torque is equal to or close to its reference value, the $3 \mathrm{VSI}$ voltage vectors should be arranged in symmetrical order.

\section{Experimental result}

The test bench used to validate the proposed control algorithm is made up of a $1 \mathrm{Kw} / 380 / 50 \mathrm{~Hz}$ squirrel cage induction motor fed by a 2-level IGBT voltage source inverter (Figure 7).

The whole control algorithm (Adaptive speed and flux observer, DTC algorithm and PI speed regulator) is implemented in a single fixed-point TMS320F240 DSPbased development board from Texas Instruments within less than $100 \mu \mathrm{s}$ of time computing. The digital control signals of the power components are generated by the DSPcontroller via PWM outputs. The control frequency is about $10 \mathrm{Khz}$. Voltage and current variables are measured by Halleffect sensors and sampled at the same frequency. A mechanical speed tachometer is mounted on the motor's shaft only to allow comparison between estimated and measured speed. The tachometer's signal is not used in the closed-loop speed control

A series of experimental results are depicted, which represent the performances of the flux and speed adaptive observer under several conditions in association with the the DTC strategies. They prove the effectiveness of the adaptive observer in general and especially in association with the DSVM-DTC strategy,. The whole control algorithm was implemented on a single DSP-controller board within a reasonable computing time, which gives result to a good performance/ease of implementation ratio.

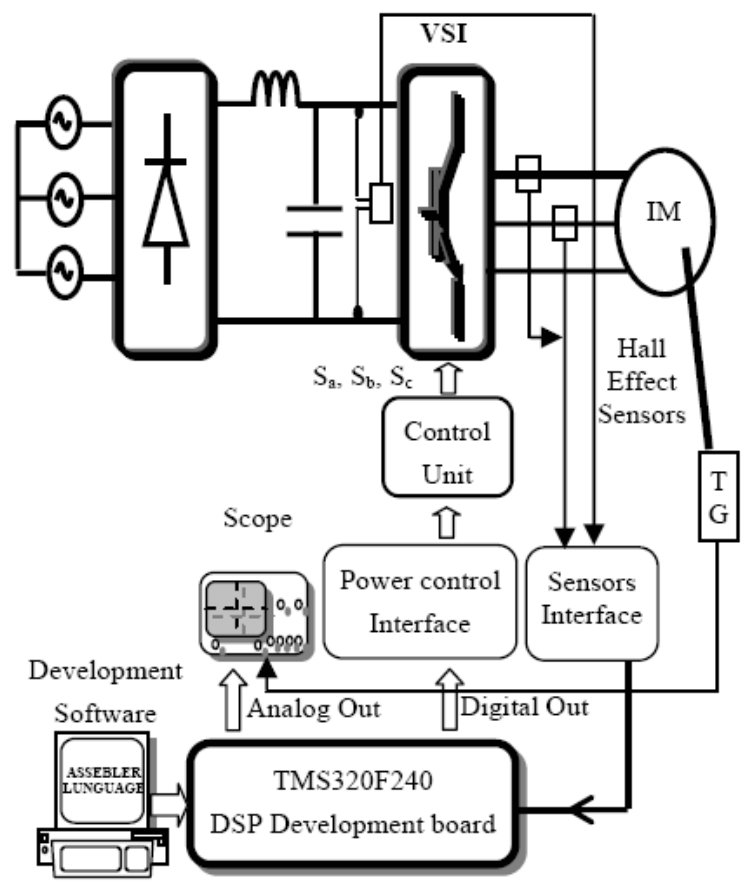

Fig. 7. Experimental system scheme

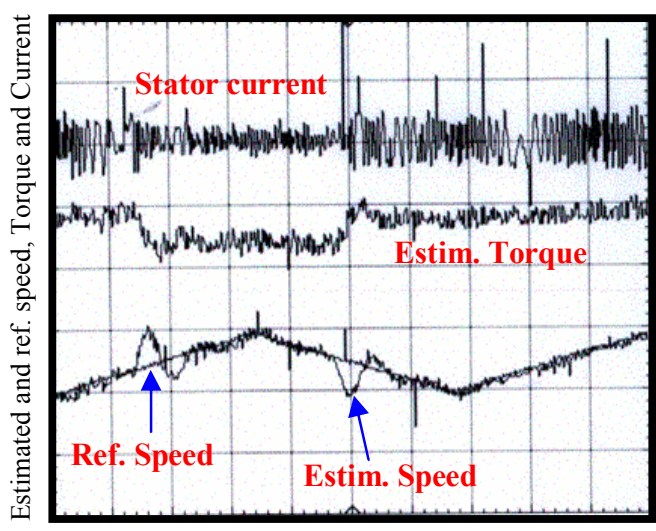

Time (S)

a) Conventional DTC

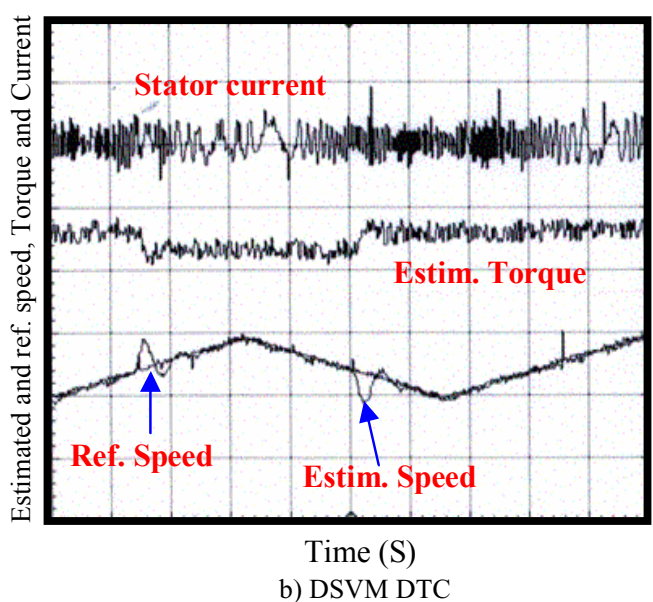

Fig. 8 Current, Torque and Speed responses

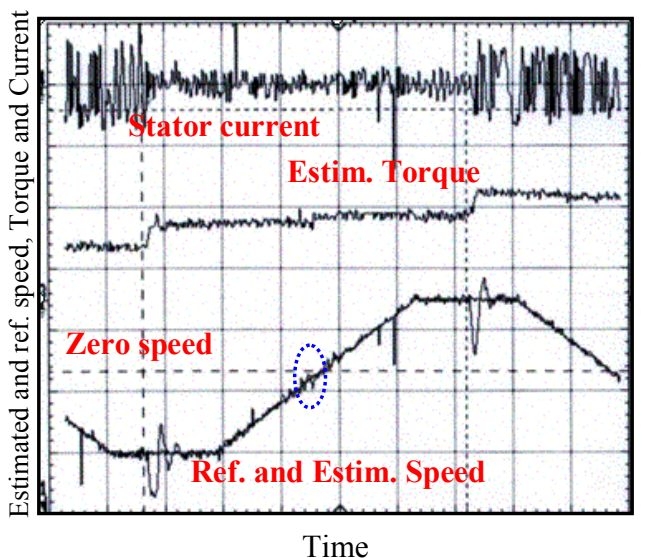

a) Conventional DTC 


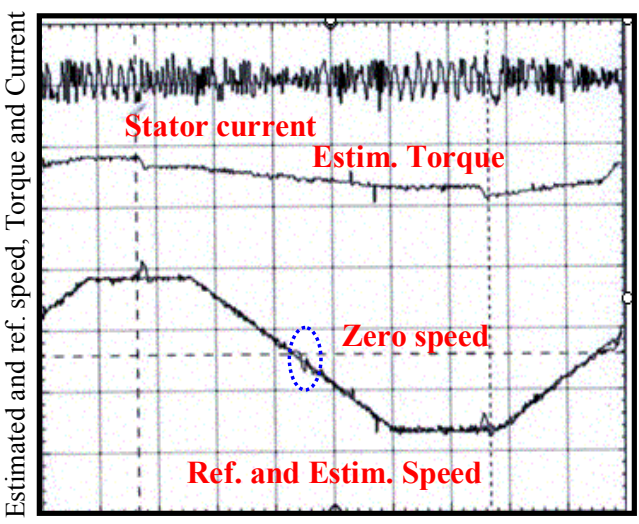

Time

b) DSVM DTC

Fig. 9 Speed reversal operation

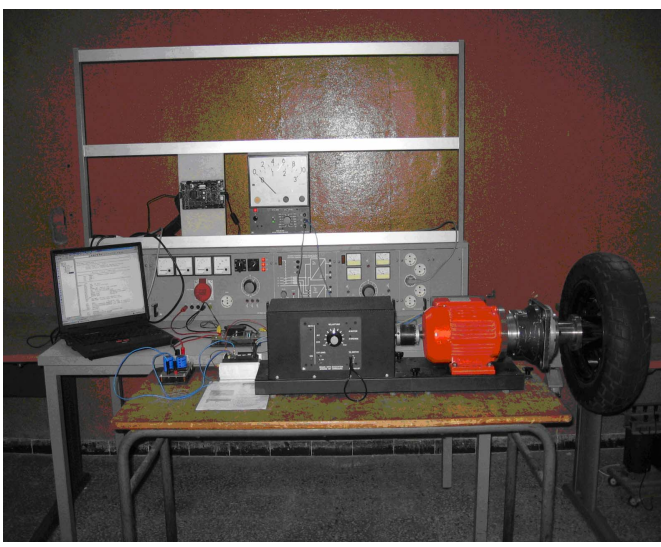

Fig. 10 Experimental prototype for Laboratory

\section{Conclusion}

This paper has presented two switching techniques for DTC of IM motor drives associated to an adaptive speed observer performed by a DSP controller. The torque pulsation and the speed ripples can be significantly reduced by invoking zero switching states and/or increasing switching frequency for the same sampling frequency.

With the experimental results it has been verified that the DSVM-DTC strategy allows the torque, the rotor speed and the current ripple to be reduced in comparison to the basic DTC strategy.

\section{Appendix}

Induction motor data

$1 \mathrm{Kw} \quad$ Rated power.

2830rpm Rated speed.

220v Rated voltage.

$4.67 \Omega \quad$ Stator resistance.

$8 \Omega \quad$ Rotor resistance.

$0.347 \mathrm{H} \quad$ Stator inductance.
$0.374 \mathrm{H}$
Rotor inductance.
$0.366 \mathrm{H}$
Mutual inductance.
$0.003 \mathrm{Kg} \cdot \mathrm{m}^{2} \quad$ Motor-Load inertia
1
\# of pole pairs.

\section{Reference}

[1] Giuseppe S. Buja, , and Marian P. Kazmierkowski, Direct Torque Control of PWM Inverter-Fed AC Motors-A Survey, IEEE Tran. ON Ind ELEC.,VOL. 51, NO. 4, AUGUST 2004.

[2] Neacsu D.O. and Rajashekara K., "Comparative Analysis of TorqueControlled IM Drives with Applications in Electric and Hybrid Vehicles", IEEE Transactions on Power Electronics, pp. 240-247, Vol 16, No 2, March 2001.

[4] T.G. Habetler, F. Profumo, M. Pastorelli, L.M. Tolbert, Direct torque control of induction machines using space vector modulation, IEEE Trans. Ind. Appl. 28 (5) (1992) 1045-1053.

[5] Y.S. Lai, J.H. Chen, A new approach to direct torque control of induction motor drives for constant inverter switching frequency and torque ripple reduction, IEEE Trans. Energy Convers. 16 (3) (2001) 220 227.

[6] D. Casadei, G. Serra, A. Tani, Improvement of direct torque control performance by using a discrete SVM technique, in: Proceedings of the 29th IEEE Power Electronics Specialists Conference (PESC), vol. 2, 1998, pp. 997-1003.

[7] D. Casadei, G. Serra, A. Tani, Implementation of a direct control algorithm for induction motors based on discrete space vector modulation, IEEE Trans. Power Electron. 15 (4) (2000).

[8] F. Khoucha, K. Marouani, A. Kheloui and K. Aliouane, "Experimental Performance Analysis of Adaptive Flux and Speed Observers for Direct Torque Control of Sensorless Induction Machine Drives", in Proc. IEEEPESC2004, Aachen, Germany. 